\title{
FORMATION OF WEAR-RESISTANT COATINGS OF WORKING SURFACES OF TECHNOLOGICAL EQUIPMENT BASED ON ZIRCONIUM OXIDE AND COBALT FILMS BY MAGNETRON SPUTTERING METHOD
}

\author{
Malyukov S.P \\ Southern Federal University, Taganrog, Russia; The Department of Electronic Apparatuses \\ Design; Dr. of Eng. sc., Professor, Corresponding Member of the Russian Academy of \\ Natural Sciences (RAS) \\ Kovalev A. V
}

Southern Federal University, Taganrog, Russia; The Department of Electronic Apparatuses Design; Dr. of Eng. sc, Professor

\section{Saenko A.V}

Southern Federal University; Taganrog, Russia;

The Department of Electronic Apparatuses Design; cand. of Eng. sc., Associate Professor.

\section{Klunnikova Yu.V}

Southern Federal University; Taganrog, Russia;

The Department of Electronic Apparatuses Design; cand. of Eng. sc., Associate Professor

\section{Timoshchenko D.V}

Southern Federal University; Taganrog, Russia; Department of Electronics, Radio Engineering and Communication Systems; Postgraduate Student

\section{Zinovyev S.S.}

Southern Federal University; Taganrog, Russia; Department of Electronics, Radio Engineering and Communication Systems; Postgraduate Student

\begin{abstract}
Key parameters of coatings application by magnetron sputtering method are presented. The mathematical model of sputtering process in magnetron sputtering system is presented. The possibility of using cobalt and zirconium films in electronic devices (memristor structures) is shown. The use of cobalt and zirconium films as wear-resistant coatings to protect the working surfaces of various technological equipment allows its term of its operation to significantly increase.
\end{abstract}


Keywords: magnetron sputtering method, sputtering modes, mathematical modelling, properties of $\mathrm{Co}$ and $\mathrm{ZrO}_{2}$ thin films, memristor structures, wear-resistant coatings.

Cite this Article: Malyukov S.P., Kovalev A. V., Saenko A.V., Klunnikova Yu.V., Timoshchenko D.V., Zinovyev S.S., Formation of Wear-Resistant Coatings of Working Surfaces of Technological Equipment Based on Zirconium Oxide and Cobalt Films by Magnetron Sputtering Method. International Journal of Civil Engineering and Technology, 11(3), 2020, pp. 120-130. https://iaeme.com/Home/issue/IJCIET?Volume=11\&Issue=3

\section{INTRODUCTION}

The improvement and development of modern methods for producing thin films is a topical task when creating wear-resistant coatings on working surfaces of technological equipment to increase their reliability and increase service life. In the present time various production processes of thin films application for electronic devices are used, a method of chemical deposition from vapor phase, deposition by thermal evaporation, vacuum-arc evaporation, a method of ionic implantation and magnetron sputtering, among which the magnetron sputtering method takes the leading positions in the nanotechnology area[1,2].

The magnetron sputtering method has considerable advantages at application of films: possibility of sputtering of various materials of complex composition and management of sputtering process, manufacturing of films at lower temperatures of a substrate, minimum porosity of films and good adhesion to a substrate.

However one of the main problems of manufacturing of films by magnetron sputtering method still has complexity of prediction of their composition and structure in view of many factors influencing the manufactured films properties.

\section{PROBLEM STATEMENT}

The magnetron sputtering method allows obtaining structures of various chemical compositions, attaining thus a high velocity of a film sputtering and keeping low temperature of a substrate. Velocity of the target material sputtering depends on the large number of parameters of films deposition process: the stream and pressure of jet gas, power of the discharge, a chemical composition and target geometric parameters, temperature in the chamber of magnetron installation, due to them it is possible to operate and stabilize discharge modes in a magnetron, that gives chance to improve the characteristics of nanocomposite layers and to optimize operation of magnetron sputtering installation. Use of magnetron sputtering in electronic devices, in particular, memristors allows expanding the limits of application of the present structures essentially.

Optimization of application process by magnetron sputtering method is carried out by means of mathematical modelling of magnetron sputtering process.

\section{MATHEMATICAL MODELLING}

Mathematical model of nanocoatings sputtering process in electrical and magnetic fields is assumed as basis. In spatial motion process between the cathode and the anode of magnetron sputtering system electron is influenced by three forces: interacting with electric field, interacting with magnetic field and collisions with atoms of working gas [3].

The equation of the particle movements looks as follows:

$$
m \frac{\mathrm{d} \mathbf{v}}{\mathrm{d} t}=\mathbf{F}_{\ni}+\mathbf{F}_{\mathrm{M}}+\mathbf{F}_{\mathrm{c}}=e \mathbf{E}+e[\mathbf{v}, \mathbf{B}]+m \frac{\mathbf{v}}{\tau}
$$


Formation of Wear-Resistant Coatings of Working Surfaces of Technological Equipment Based on Zirconium Oxide and Cobalt Films by Magnetron Sputtering Method

where $\mathbf{F}_{\ni}$ - interaction force with electric field; $\mathbf{F}_{\mathbf{M}}$ - interaction force with magnetic field; $\mathbf{F}_{\mathrm{c}}$ - collision force with atoms of working gas; $\tau$ - average time between collisions; $e$ and $m$ - charge (taking into account positive or negative) and electron mass; $\mathbf{V}-$ its motion velocity; $\mathbf{E}$ - electric field strength; $\mathbf{B}$ - magnetic field induction.

The equation (1) in projections on axe of coordinates:

$$
\begin{aligned}
& m \frac{\mathrm{d} v_{x}}{\mathrm{~d} t}=e E_{x}+e\left(v_{y} B_{z}-v_{z} B_{y}\right)+\frac{m}{\tau} v_{x}, \\
& m \frac{\mathrm{d} v_{y}}{\mathrm{~d} t}=e E_{y}+e\left(v_{z} B_{x}-v_{x} B_{z}\right)+\frac{m}{\tau} v_{y}, \\
& m \frac{\mathrm{d} v_{z}}{\mathrm{~d} t}=e E_{z}+e\left(v_{x} B_{y}-v_{y} B_{x}\right)+\frac{m}{\tau} v_{z} .
\end{aligned}
$$

Let electric and magnetic fields are directed so that their components are equal correspondingly:

$$
E_{x}=E_{0} \cos \omega t, \quad E_{y}=E_{z}=0, \quad B_{z}=B_{0}, \quad B_{x}=B_{y}=0,
$$

where $\omega_{-}$cyclic frequency of electric field.

Taking into account the formulas (3), the formulas $(2.1,2.2,2.3)$ have the following form:

$$
\begin{aligned}
& \frac{\mathrm{d} v_{x}}{\mathrm{~d} t}=\frac{e}{m} E_{x}+\frac{e B_{z}}{m} v_{y}+\frac{1}{\tau} v_{x}, \\
& \frac{\mathrm{d} v_{y}}{\mathrm{~d} t}=-\frac{e B_{z}}{m} v_{x}+\frac{1}{\tau} v_{y}, \\
& \frac{\mathrm{d} v_{z}}{\mathrm{~d} t}=\frac{1}{\tau} v_{z} .
\end{aligned}
$$

Neglecting volume charge, equations (4) are written as:

$$
\begin{aligned}
& \frac{\mathrm{d}^{2} x}{\mathrm{~d} t^{2}}-\frac{1}{\tau} \frac{\mathrm{d} x}{\mathrm{~d} t}-\omega_{0} \frac{\mathrm{d} y}{\mathrm{~d} t}=\frac{e}{m} E_{0} \cos \omega t \\
& \frac{\mathrm{d}^{2} y}{\mathrm{~d} t^{2}}-\frac{1}{\tau} \frac{\mathrm{d} y}{\mathrm{~d} t}+\omega_{0} \frac{\mathrm{d} x}{\mathrm{~d} t}=0, \\
& \frac{\mathrm{d}^{2} z}{\mathrm{~d} t^{2}}-\frac{1}{\tau} \frac{\mathrm{d} z}{\mathrm{~d} t}=0, \\
& \omega_{0}=\frac{e B_{0}}{m},
\end{aligned}
$$

where $\omega_{0}$ - cyclotron frequency. 
Let's integrate the equations $(5.1,5.2,5.3)$, accepting initial and boundary conditions, it takes the form:

$$
\begin{aligned}
& \frac{\mathrm{d} x}{\mathrm{~d} t}-\frac{1}{\tau} x-\omega_{0} y=\frac{e}{m \omega} E_{0} \sin \omega t \\
& \frac{\mathrm{d} y}{\mathrm{~d} t}-\frac{1}{\tau} y+\omega_{0} x=0 \\
& \frac{\mathrm{d} z}{\mathrm{~d} t}-\frac{1}{\tau} z=\mathrm{const},
\end{aligned}
$$

During integration, we accepted initial and boundary conditions:

$$
\begin{aligned}
& t=0 ; \quad x=0, \quad y=0,\left.\quad \frac{\mathrm{d} x}{\mathrm{~d} t}\right|_{t=0}=0 \quad,\left.\quad \frac{\mathrm{d} y}{\mathrm{~d} t}\right|_{t=0}=0 \\
& z=0,\left.\quad \frac{\mathrm{d} z}{\mathrm{~d} t}\right|_{t=0}=\dot{z}_{0}
\end{aligned}
$$

To find dependence of a particle coordinates from time let's find particular solution of the equation (7).

It is written as:

$$
\begin{aligned}
& y(t)=\frac{\omega_{0}}{\omega} \frac{e}{m} E_{0}\left[\frac{\frac{1}{\tau} \omega}{\left(\omega_{0}^{2}-\omega^{2}\right)^{2}+\frac{1}{\tau^{2}} \omega^{2}} \cos \omega t-\frac{\omega_{0}^{2}-\omega^{2}}{\left(\omega_{0}^{2}-\omega^{2}\right)^{2}+\frac{1}{\tau^{2}} \omega^{2}} \sin \omega t\right] \\
& x(t)=\frac{e}{m} E_{0}\left[\frac{\omega_{0}^{2}-\omega^{2}+\frac{1}{\tau^{2}}}{\left(\omega_{0}^{2}-\omega^{2}\right)^{2}+\frac{1}{\tau^{2}} \omega^{2}} \cos \omega t+\frac{\frac{1}{\tau} \omega-\frac{1}{\omega \tau}\left(\omega_{0}^{2}-\omega^{2}\right)}{\left(\omega_{0}^{2}-\omega^{2}\right)^{2}+\frac{1}{\tau^{2}} \omega^{2}} \sin \omega t\right] \\
& z(t)=\dot{z}_{0} \tau\left(e^{\frac{t}{\tau}-1}\right) .
\end{aligned}
$$

On the basis of analytical solution of the equations system (7) presented in formulas (911) the particle motion trajectory is made.

The diagram of the particle trajectory in dimensionless units is shown in the figure,

when $\left(\omega=\omega_{0}=\frac{1}{\tau}\right)$. 
Formation of Wear-Resistant Coatings of Working Surfaces of Technological Equipment Based on Zirconium Oxide and Cobalt Films by Magnetron Sputtering Method

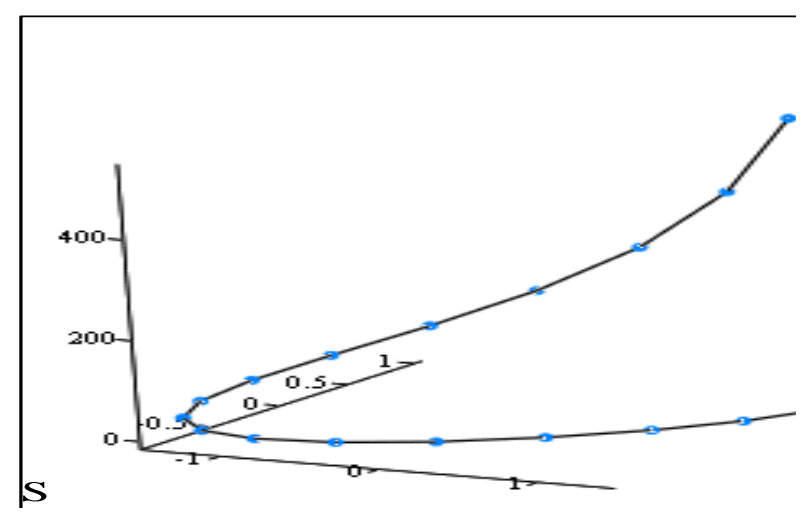

Figure 1. Three-dimensional particle trajectory

The received three-dimensional particle trajectory allows optimizing magnetron sputtering process that contributes to improvement of quality of the film being sputtered. Modelling of magnetron sputtering processes which parameters have complicated dependence from each other, allows reducing quantity of the experiments necessary for search of the optimum mode of thin films application.

\section{EXPERIMENT}

Constructions of modern magnetron sputtering systems are rather diverse. Advantage of the magnetron sputtering system in which unbalanced dual magnetrons with a field of the closed type are used, working in a pulse mode is the magnetic system mounted in the water-cooled holder, not allowing penetration of contamination into the working chamber [1]. Planetary magnetron systems allow creation of higher density of current (more than $2 \mathrm{~mA} / \mathrm{cm}^{2}$ ) and to attain high velocities of deposition (more than $24 \mathrm{~nm} / \mathrm{c}$ ) thus value of homogeneity of a sputtered film remains high.

For formation of cobalt and zirconium oxide films by the magnetron sputtering method on a glass substrate, VSE-PVD-DESK-PRO installation for deposition of materials by the magnetron sputtering method in vacuum was used, where argon (fig. 2) was used as working gas. One of the modules of the magnetron installation is designed for deposition of metals ( 3 inch targets), the other module is designed for deposition of semiconductors and dielectrics ( 2 inch targets).

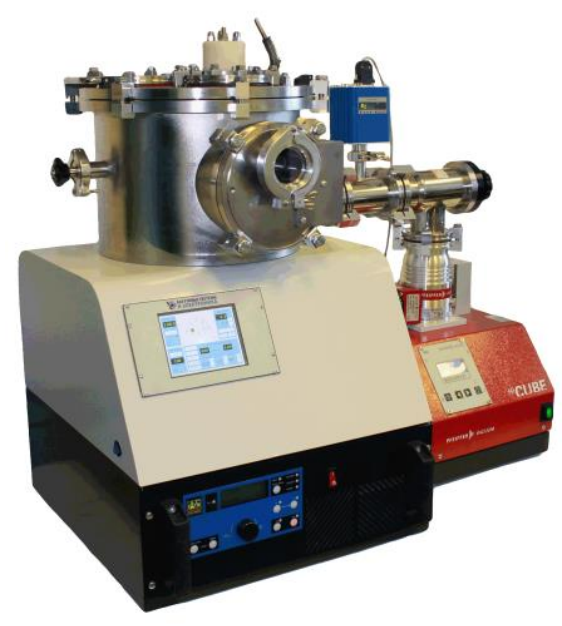

Figure 2. VSE-PVD-DESK-PRO desktop installation for deposition of materials by the magnetron sputtering method in vacuum 
General characteristics of VSE-PVD-DESK-PRO installation:

- Oil-free pumpdown system provides high purity of deposited coatings.

- Ultimate residual pressure is $1 * 10^{-7}$ mbar.

- Discharge capacity is up to $1.5 \mathrm{~kW}$.

- Homogeneity of applied coatings is $\pm 10 \%$.

- Stepless control range of output average power is from 0.1 to $3 \mathrm{~kW}$.

- Substrate holder with step motor and optical sensors provides position accuracy up to 0.5 mm.

- Substrates maximum diameter is $90 \mathrm{~mm}$.

Different metals (target materials are: $\mathrm{Al}, \mathrm{TiO}_{2}, \mathrm{Si}, \mathrm{Cr}, \mathrm{Co}, \mathrm{Cu}, \mathrm{SiO}_{2}, \mathrm{Al}_{2} \mathrm{O}_{3}, \mathrm{Ti}$ ) have unequal velocity of film sputtering in comparison with metal oxides on their basis. Relative velocity values of application of films of different oxides, metals at sputtering with ions of $\mathrm{Ar}^{+}$with power $700 \mathrm{eV}$ are presented on the diagram (fig. 3). [4]

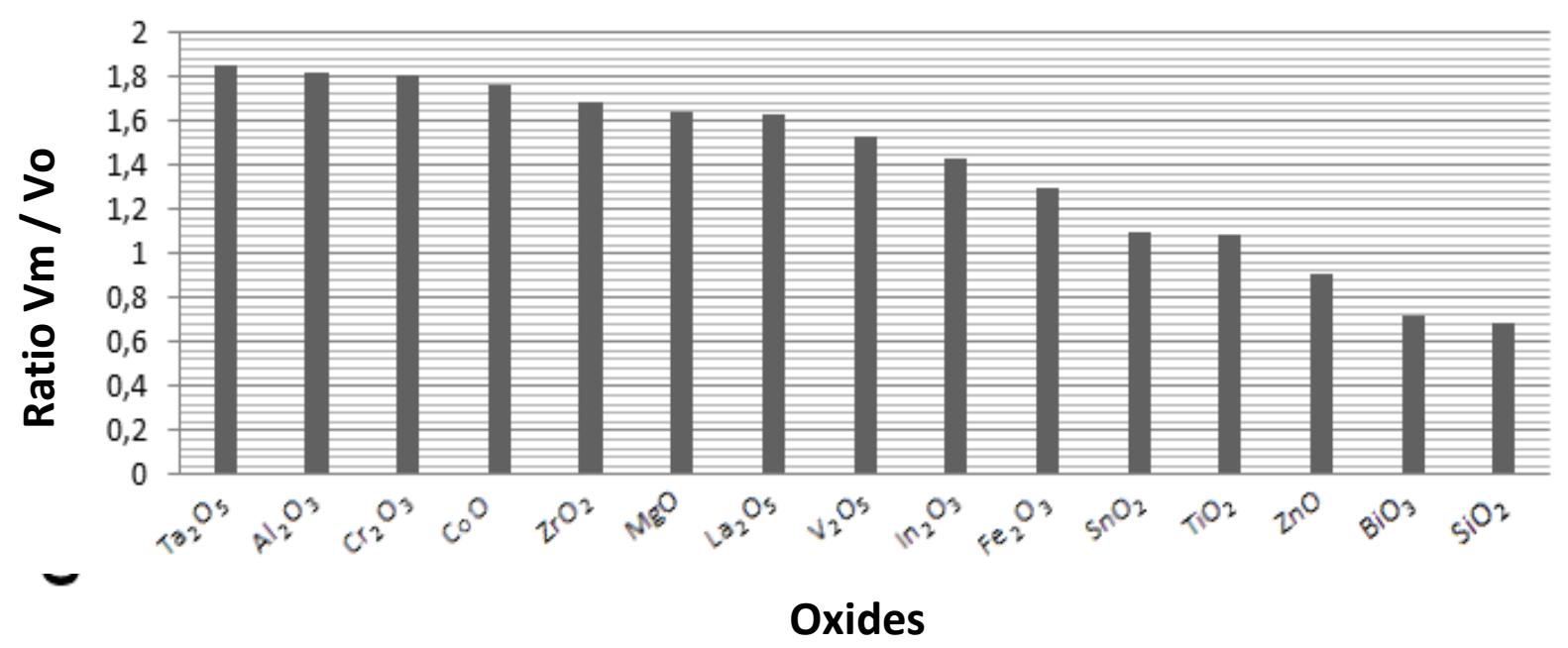

Figure 3. Ratio of metals application velocity to oxides on their basis application velocity (Vm / Vo) at sputtering with argon ions.

It is seen from the diagram, that the ratio range of materials application velocity is great enough. Sampling of targets for experiments, such as cobalt and zirconium, resulted from the fact that the material has high ratio $\mathrm{Vm} / \mathrm{Vo}$ and has high wear resistance and hardness at high temperatures $\left(\mathrm{t}_{\mathrm{melt}}-1493{ }^{\circ} \mathrm{C}\right)$. Practice of use of various targets has shown that application of such materials as cobalt is well correlated in the field of researches of resistive switching over in memristor structures [5-9]. Process of deposition of cobalt and zirconium films is characterized by the following control effects: pressure of working gas $\mathrm{P}$, temperature from substrate $\mathrm{T}$ and a discharge current $\mathrm{I}$, distance substrate-target $\mathrm{D}$, i.e. all specified effects influence process of sputtering and can be changed. Before cobalt $(\mathrm{Co})$ application on a glass substrate with the size $17 \times 25 \mathrm{~mm}$, there was made its ionic cleaning at pressure $3 * 10^{-3} \mathrm{mbar}$ in VSE-PVD-DESK-PRO magnetron installation chamber. The target of three-inch Co 99,95 $\%$ of purity with thickness (d) $4 \mathrm{~mm}$ was applied on a glass substrate at the following operating mode of the magnetron: $\mathrm{P}=340 \mathrm{~W}, \mathrm{I}=0.42 \mathrm{~A}, \mathrm{U}=400 \mathrm{~V}$, pressure in the chamber (p) was $5^{*} 10^{-3}$ mbar, working gas was argon (Ar). Duration of film deposition on the glass substrate was 5 minutes. Optimization of parameters (P, T, I, D) will define productivity of the sputtering process, i.e. sputtering velocity in unit time. 
Formation of Wear-Resistant Coatings of Working Surfaces of Technological Equipment Based on Zirconium Oxide and Cobalt Films by Magnetron Sputtering Method

Formation of films is influenced most essentially by pressure of working gas in the chamber. In research of formation of films by the magnetron sputtering method we stopped on argon pressure value $\mathrm{p}=1-3^{*} 10^{-3}$ mbar. In voltage-current characteristic research, values of current were changed with step $0.1 \mathrm{~A}$, where as a target there was $(\mathrm{Co})$ in gas medium of argon (Ar). Results of output parameter values in voltage-current characteristic research are presented in table 1. From the data presented in the table it is seen, that at constant pressure (p) and increasing current (I) the discharge voltage $\left(\mathrm{U}_{\mathrm{d}}\right)$ grows. As it is obvious, that at constant value of current and raising value of pressure discharge voltage drops.

Table 1. VSE-PVD-DESK-PRO installation discharge voltages; material Co; working gas - Ar according to BAX research.

\begin{tabular}{|c|c|c|c|c|}
\hline Experiment No & $\mathbf{I}, \mathbf{A}$ & \begin{tabular}{|c|} 
Discharge voltage $U_{d}$, \\
V, at pressure $p=1 * 10^{-3}$ \\
mbar
\end{tabular} & \begin{tabular}{|c|} 
Discharge voltage $U_{d}$, \\
V, at pressure $\mathbf{p}=2 * 10^{-3}$ \\
mbar
\end{tabular} & \begin{tabular}{|c|} 
Discharge voltage $U_{d}$, \\
V, at pressure $p=3^{*} 10^{-3}$ \\
mbar
\end{tabular} \\
\hline 1 & 0.1 & 356 & 318 & \begin{tabular}{|c|}
299 \\
\end{tabular} \\
\hline 2 & 0.2 & 360 & 320 & 304 \\
\hline 3 & 0.3 & 362 & 324 & 308 \\
\hline 4 & 0.4 & 365 & 326 & 309 \\
\hline 5 & 0.5 & 366 & 327 & 311 \\
\hline 6 & 0.6 & 370 & 330 & 314 \\
\hline 7 & 0.7 & 375 & 334 & 315 \\
\hline 8 & 0.8 & 380 & 339 & 318 \\
\hline 9 & 0.9 & 388 & 345 & 322 \\
\hline 10 & 1.0 & 402 & 352 & 327 \\
\hline
\end{tabular}

Data from the table shows, that there are two alternatives of selection of current and pressure parameters in the chamber for determination of the discharge voltage value, for example, to get parameter (327) of discharge voltage it is necessary either to set current value $1 \mathrm{~A}$ and pressure $-3^{*} 10^{-}$ ${ }^{3}$ mbar, or to set current value $0.5 \mathrm{~A}$ and pressure $-2 * 10^{-3} \mathrm{mbar}$. The table bears the important message to the further scientific researches and allows choosing the optimal mode of thin films application on a substrate by the magnetron sputtering method. On the basis of results of the presented table the diagram of dependence of discharge voltage from discharge current strength, presented on fig. 4 is made, it shows that discharge voltage smoothly grows with increase in discharge current strength at different values of pressure of working gas in the chamber of VSE-PVD-DESK-PRO magnetron sputtering system and gives the possibility to define the optimum values of parameters ( $\left.\mathrm{p}, \mathrm{I}, \mathrm{U}_{\mathrm{d}}\right)$.

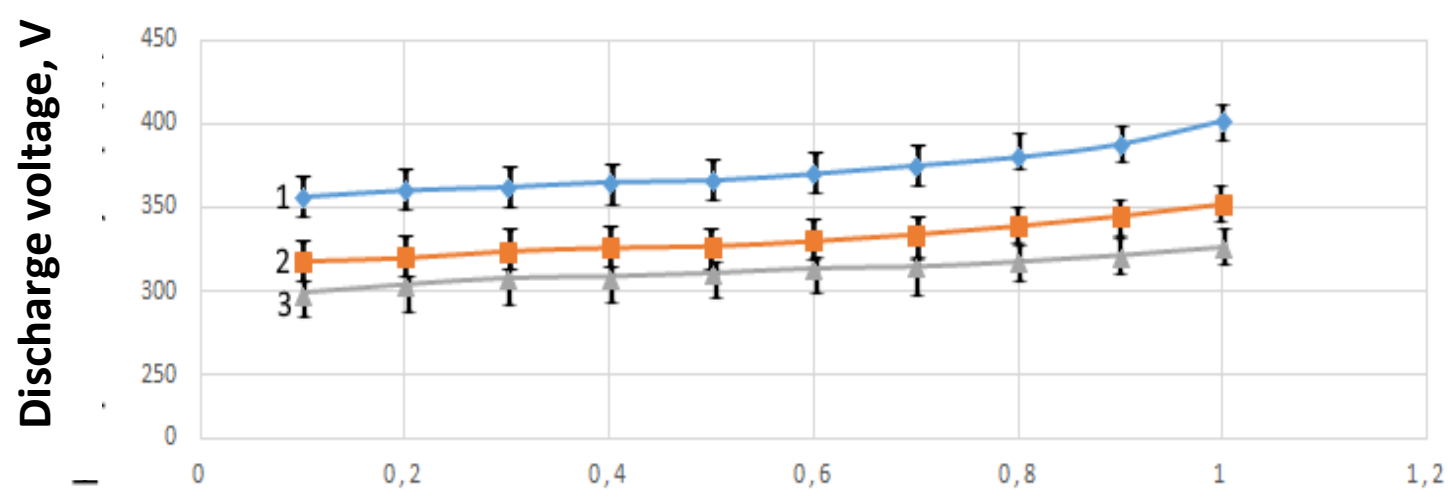

Discharge current strength, A

Figure 4. Dependences of pressure of the discharge $U_{d}$, [B] from discharge current strength $I$, [A] (material Co; working gas $-\mathrm{Ar}$ ). $1-\mathrm{U}_{\mathrm{d}},[\mathrm{B}]$ at pressure $\mathrm{p}=1 * 10^{-3}$ mbar; $2-\mathrm{U}_{\mathrm{d}},[\mathrm{B}]$ at pressure $\mathrm{p}=2 * 10^{-3}$ mbar; $3-\mathrm{Ud},[\mathrm{B}]$ at pressure $\mathrm{p}=3 * 10^{-3}$ mbar. 
The velocity-time diagram of material sputtering for various values of a discharge current with increasing value of working gas pressure in the chamber is shown in Figure 5, where changing pressure directly influences sputtering velocity, change of discharge current strength is weakly shown. It is possible to achieve required values of sputtering velocity of coated films by means of regulation gas pressure in the chamber of magnetron-sputtering system and discharge current strength.

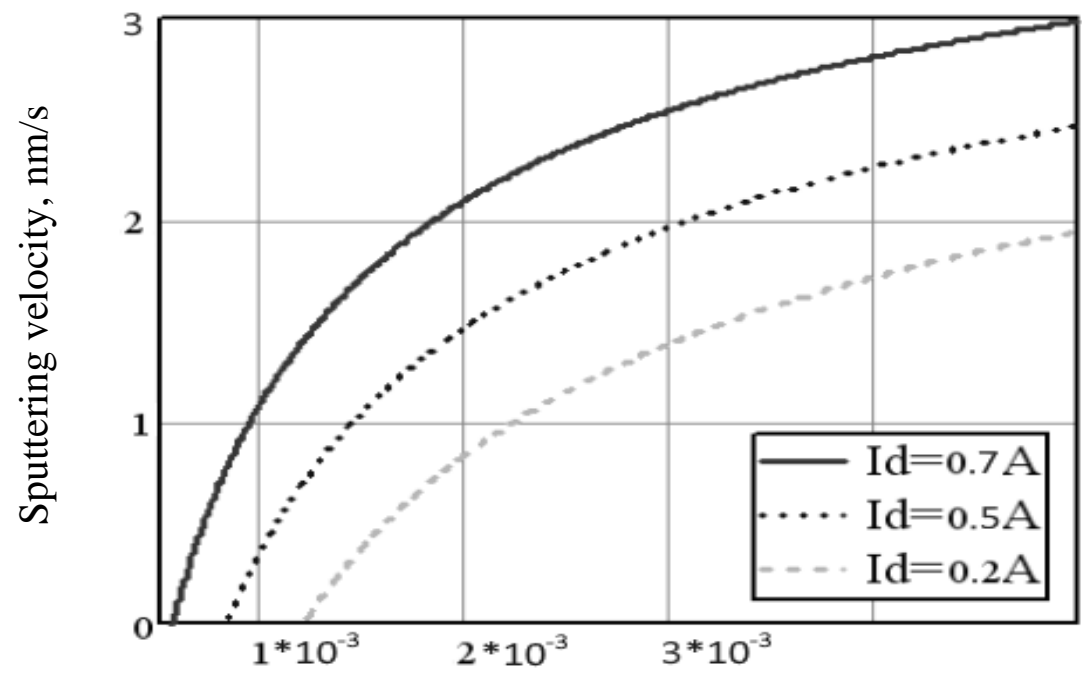

Gas pressure, mbar

Figure 5 Sputtering velocity diagram for various values of a discharge current

The executed researches of forming of $\mathrm{Co}, \mathrm{ZrO}_{2}$ oxide films by method of the magnetron sputtering have allowed to approach closely to a development of memory of a new generation based on memristors [10-14].

\section{MEMRISTOR STRUCTURE}

For application of memristors as memory elements, the simple structure is used. It consists of conductors between which there is a layer from a material with properties of memristancy. Under the influence of the applied voltage, the layer can change its conduction $[15,16]$. According to the analysis of available materials for resistive memory with random access (ReRAM) executed in the research [17] it has been established that from a large number of oxides used in (ReRAM) zirconium oxide $\left(\mathrm{ZrO}_{2}\right)$ has significant criteria (there are high dielectric permeability $(\varepsilon=22-25)$, high breakdown field $(E=15-20 \mathrm{MV} / \mathrm{cm})$, high thermal and chemical stability) for development of resistive memory devices. Memristor structure with use of Co is shown in Figure 6 [17]. The thin layer of a semiconducting material based on $\mathrm{ZrO}_{\mathrm{x}}$ is placed between two metal contacts: top (W) and bottom (Co) electrodes. 
Formation of Wear-Resistant Coatings of Working Surfaces of Technological Equipment Based on Zirconium Oxide and Cobalt Films by Magnetron Sputtering Method

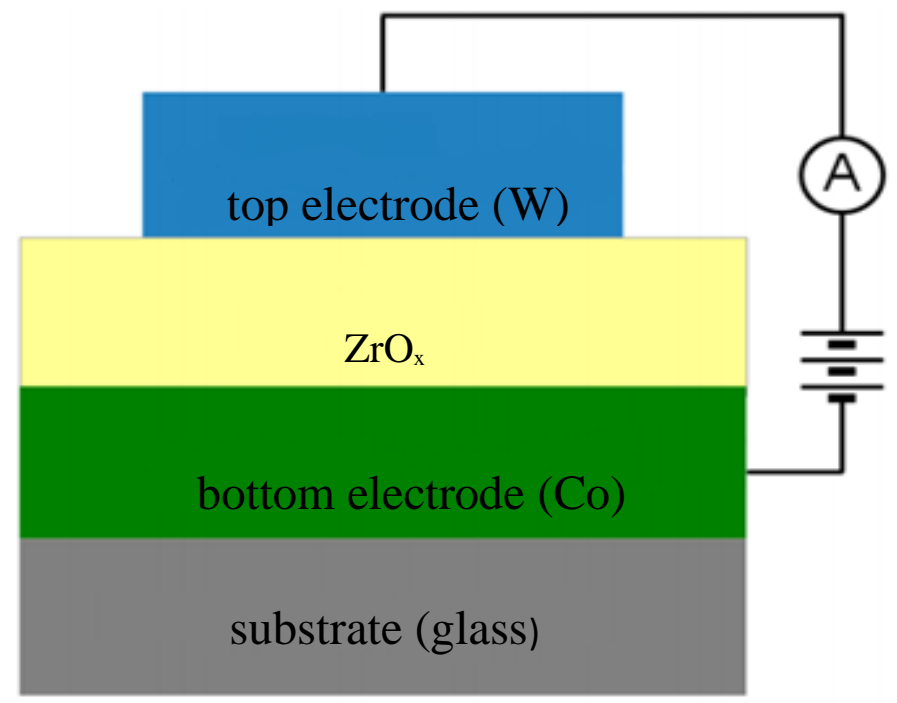

Figure 6. Memristor structure diagram

The construction of memristor with the $\mathrm{Co} / \mathrm{ZrO}_{2} / \mathrm{W}$ structure made on a glass substrate with dimensions $17 \times 25 \mathrm{~mm}$ by method of magnetron sputtering is taken for a basis to work out technological processes of manufacturing of memristors components [18].

Further, a procedure of so-called forming is executed, it is necessary to product a marked memristor result of this structure. For this purpose, a unipolar (positive) sweep of current is executed. The current amplitude increases gradually and each time changes of memristor voltage-current characteristic are registered. Further, the unipolar sweep is switched off and the bipolar sweep is switched on at gradual increase of the sweep current amplitude. The voltage-current characteristic of the experimental memristor sample based on the $\mathrm{Co} / \mathrm{ZrO} 2 / \mathrm{W}$ structure made by means of the NanoEducator scanning probe microscope and the Keithley 4200-SCS semiconductor device characterization system gets the typical hysteretic form shown in Figure 7.

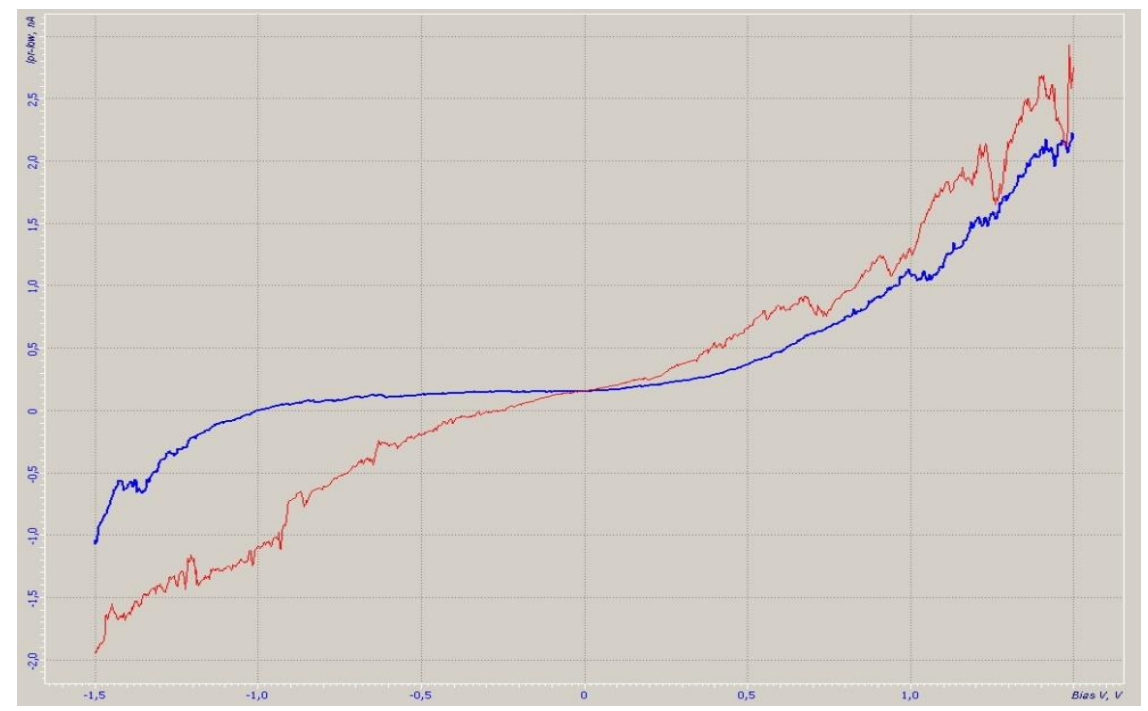

Figure 7. The voltage-current characteristic of the experimental memristor sample based the $\mathrm{Co} / \mathrm{ZrO}_{2} / \mathrm{W}$ structure got as a result of the "forming" process 


\section{CONCLUSIONS}

As a result of experiments on the study of the process of sputtering in the environment of $\mathrm{Ar}$ by magnetron sputtering of zirconium and cobalt oxide films, the dependence of the discharge voltage on the current strength and also the sputtering rate at various values of the discharge current are determined. The main modes of the magnetron sputtering of cobalt and zirconium for technological equipment devices are determined.

A mathematical model is obtained for the formation of zirconium and cobalt oxide films by magnetron sputtering, which includes mathematical expressions of the dependence of particle coordinates on time and a three-dimensional particle trajectory.

The possibility of realizing the structure of memristors based on $\mathrm{Co} / \mathrm{ZrO}_{2} / \mathrm{W}$ using the technology of magnetron sputtering, which allows to realize the possibility of creating a new generation of memory devices, is shown.

The presented technology can be used in various sectors of the national economy, in particular, in technological equipment.

The research was carried out under the project "Creation of high-tech production of hardware and software systems for processing agricultural raw materials based on microwave radiation" (Agreement with the Ministry of Education and Science of the Russian Federation № 075-11-2019-083 of 20.12.2019, SFedU Agreement № 18 of 20.09.2019, number of work in SFedU № XD/19-25-RT).

\section{REFERENCES}

[1] Francis F. Chen. Industrial applications of low - temperatures plasma physics // Phys. Plasmas vol. 2, n. 6, June 1995, P. 2164-2175.

[2] Kuzmichev A. I. Magnetron Sputtering Systems, vol. 1, Introduction to the physics and technology of magnetron sputtering, Kiev, 2008.

[3] Ismagilov F.R., Maksudov D.V. A mathematical model of the process of deposition of nanocoatings in electric and magnetic fields // Bulletin of the Voronezh State Technical University, 2012, P. 17-20.

[4] Udovichenko S.Yu. Beam-plasma technologies for creating materials and devices for micro- and nanoelectronics // Educational-methodical manual, Publishing house of the Tyumen State University, 2014.

[5] Dewei Chu, Adnan Younis, Sean Li. Enhancement of Resistance Switching in Electrodeposited Co-ZnO Films // International Scholarly Research Network - ISRN Nanotechnology, V. 2012.

[6] Malyukov S.P., Zinoviev S.S., Kovalev A.V., Starykh A.A. Multilayer magnetic films for hard disks // International Journal of Applied Engineering Research ISSN 0973-4562. 2017. V. 12, P. 11874-11877.

[7] Dzhumaliev A.S., Nikulin Yu.V. Influence of argon pressure on the texture and microstructure of cobalt films deposited by magnetron sputtering // Not. Sarat. Un. New ser. Ser. Physics. 2017. Vol. 17, issue 4, P. 254-262.

[8] Utkin K.E., Torgashin S.I., Khoshev A.V. Controlled synthesis of thin films obtained by magnetron sputtering // Measurement. Monitoring Control. The control. - 2018. - No. 2 (24). - P. 41-46.

[9] Saghatelyan G.R., Shishlov A.V. Analysis of the distribution of the thickness of a thinfilm coating during magnetron sputtering in installations with planetary movement of the substrate // Science and Education. MSTU named after N.E. Bauman. Electron. journal 2014. No. 11. P. 458-481. 
Formation of Wear-Resistant Coatings of Working Surfaces of Technological Equipment Based on Zirconium Oxide and Cobalt Films by Magnetron Sputtering Method

[10] Strukov D.B., Snider G.S., Stewart D.R., Williams R.S. The missing memristor found // Nature letters. 2008. V.453, P. 80-83.

[11] Pergament A. L., Khanin S. D. Electronic switching in thin layers of transition metal oxides // Not. Russian State Pedagogical University named after A.I. Herzen. Natural and exact sciences April 2007 No. 7 (26) P. 69-86.

[12] Gorshkov O.N., Kasatkin A.P., Antonov D.A., Antonov I.N., Belov A.V. Resistive switching in MDM structures based on $\mathrm{GeO}_{2}$ and $\mathrm{ZrO}_{2}$ films // Proceedings of the XVII International Symposium "Nanophysics and Nanoelectronics", Vol. 2 Section 3. Semiconductor nanostructures: electronic, optical properties, formation methods, Nizhny Novgorod, March 11-15, 2013, P. 412-413.

[13] Antonov D.A., Filatov D.O., Gorshkov O.N., Dudin A.Yu., Sharapov A.N., Zenkevich A.V., Matveev Yu.A. The study of resistive switching in thin $\mathrm{HfO}_{2} / \mathrm{Si}$ films by the combined STM/AFM method // Solid State Physics, Bulletin of the Nizhny Novgorod University named after N.I. Lobachevsky, 2013, No. 2 (2), P. 17-21.

[14] Omid Kavehei. Memristive Devices and Circuits for Computing, Memory and Neuromorphic Applications // School of Electrical \& Electronic Engineering Faculty of Engineering, Computer \& Mathematical Sciences The University of Adelaide, Australia. 2011, December.

[15] Eliseev N. Memristors and crossbars: nanotechnologies for processors // Electronics: Science, Technology, Business, 2010, No. 8, P. 84-89.

[16] Joshua Y.J., Byung J.Ch., Min-Xian Z., Torrezan Antonio C., Strachan J.P., Williams St.R. Memristive Devices for Computing: Mechanisms // Applications and Challenges. HP Laboratories, HPL-2013-48.

[17] Klunnikova Yu.V., Malyukov S.P., Timoshchenko D.V. The use of zirconium oxide $\left(\mathrm{ZrO}_{2}\right)$ in memristor structures // Report collection: Modern information technologies: trends and development prospects: proceedings of the XXVI Scientific Conference of the Southern Federal University, 2019, P. 182-184.

[18] Nickel J. Memristor Materials Engineering: From Flash Replasement Towards a Universal Memory // HP Lab. IEDM Advansed Memory Technology Workshop. 2011, 4 December. 